\title{
CAN WE RELY ON PROCALCITONIN IN THE DIAGNOSIS OF LATE ONSET NEONATAL
} SEPSIS?

\author{
N. Athiraman ${ }^{1}$, S. Krishnamoorthy ${ }^{1}$, M. Guy ${ }^{2}$, R. Agarwal ${ }^{1}$ \\ ${ }^{l}$ Neonatal Unit, ${ }^{2}$ Department of Biochemistry, Salford Royal Hospital, Salford, UK
}

Aims:

1. To explore the usefulness of Procalcitonin(PCT) assay in the diagnosis of late onset neonatal sepsis(LONS)

2. To compare the diagnostic usefulness of Procalcitonin with $\mathrm{C}$ - reactive protein(CRP)

Methods: Infants $\geq 48$ hours old and being investigated for LONS were recruited after informed consent. The sepsis episodes were categorised into 3 groups: True positive, True negative and Possible sepsis on the basis of clinical symptoms, results from blood culture or other sterile body fluids and raised CRP or thrombocytopenia.

Results: A total of 219 sepsis episodes in 121 infants were evaluated. There were 79(36\%) true positive, $68(31 \%)$ possible sepsis and 71(33\%) true negative episodes of sepsis. The sensitivity and specificity were calculated for true positive versus true negative episodes; and the cut-off used for CRP and procalcitonin was 10 and 0.5 respectively. The sensitivity of procalcitonin and CRP was $68 \%$ and $56 \%$ respectively whereas the specificity was $60 \%$ and $85 \%$.

\begin{tabular}{|l|l|l|l|l||}
\hline & Sensitivity (\%) & Specificity (\%) & $\begin{array}{l}\text { Positive predictive } \\
\text { value (\%) }\end{array}$ & $\begin{array}{l}\text { Negative predictive } \\
\text { value (\%) }\end{array}$ \\
\hline \begin{tabular}{l|l|l|l|} 
Procalcitonin \\
(overall)
\end{tabular} & $68(56-78)$ & $60(47-72)$ & $67(56-77)$ & $61(48-73)$ \\
\hline CRP (overall) & $56(44-67)$ & $85(74-92)$ & $81(69-91)$ & $61(50-71)$ \\
\hline $\begin{array}{l}\text { Procalcitonin (CNS } \\
\text { excluded) }\end{array}$ & $92(73-99)$ & $60(47-72)$ & $46(31-61)$ & $95(83-99)$ \\
\hline $\begin{array}{l}\text { CRP } \\
\text { (Staphylococcus } \\
\text { epidermidis [CNS] } \\
\text { excluded) }\end{array}$ & $58(37-78)$ & $85(74-92)$ & $58(37-78)$ & $85(74-92)$ \\
\hline
\end{tabular}

[Diagnostic tests: Procalcitonin vs CRP in LONS]

Conclusion: Procalcitonin is a useful marker of LONS. In this study, PCT is more sensitive but less specific than CRP in the diagnosis of late onset neonatal sepsis. PCT could be used as a useful adjuvant to CRP in the evaluation of late onset neonatal sepsis. 